\title{
ANALISIS PENGARUH JALAN BYPASS MATARAM-GERUNG TERHADAP NILAI TANAH DI LOMBOK BARAT
}

\author{
Ahmad Zaki Mubarak ${ }^{1)}$; Heni Sulastri ${ }^{2}$ \\ 1) ahmadzakimubarak27@gmail.com,, Politeknik Keuangan Negara STAN \\ 2) heni.sulastri@pknstan.ac.id,, Politeknik Keuangan Negara STAN* \\ *email korespondensi
}

\begin{abstract}
The purpose of this study was to research the difference in land values between the conditions before and after the Mataram-Gerung bypass road was built and to find out the magnitude of the difference in land prices. The research was conducted in West Lombok Regency by collecting secondary data from the Office of Regional Revenue, related literature studies, and applicable regulations. The data obtained are sixty data from 2013 to 2018 consisting of thirty data on land sale and purchase transactions before and after the construction of the bypass road. Then from the sixty transaction data, adjustments were made to each data so that the land value obtained had a comparable value to be used as material for analysis of the independent sample t-test difference test to find out whether the two samples significantly had the same average or not. The results showed that there was a significant difference in land value between conditions before and after the Mataram-Gerung bypass road was built. The difference in land values obtained in the research was $141.5 \%$.
\end{abstract}

Keywords : land values, land prices, the Mataram-Gerung bypass road

\begin{abstract}
Abstrak
Tujuan penelitian ini untuk mengetahui perbedaan nilai tanah dan harga tanah antara kondisi sebelum dan sesudah jalan bypass Mataram-Gerung dibangun. Penelitian ini dilakukan di Kabupaten Lombok Barat. Data yang digunakan pada penelitian ini adalah data sekunder dari Badan Pendapatan Daerah. Penelitian ini memanfaatkan penelitian sejenis yang pernah ada, dan peraturan-peraturan yang berlaku di Indonesia. Data yang diperoleh berjumlah enam puluh data dari tahun 2013 sampai 2018, terdiri dari masing-masing tiga puluh data transaksi jual beli tanah sebelum dan sesudah dibangunnya jalan bypass. Atas data transaksi dalam penelitian ini, dilakukan penyesuaian terhadap masing-masing data. Hal ini dilakukan agar nilai tanah memiliki nilai yang sebanding untuk digunakan sebagai bahan analisis. Analisis menggunakan analis uji beda independent sample t-test untuk mengetahui apakah kedua sampel yang digunakan dalam penelitian ini mempunyai rata-rata yang sama atau tidak, secara signifikan. Hasil penelitian menunjukkan bahwa terdapat perbedaan nilai tanah yang signifikan antara kondisi sebelum dan sesudah dibangun jalan bypass Mataram-Gerung. Perbedaan nilai tanah yang diperoleh dalam penelitian adalah sebesar $141,5 \%$.
\end{abstract}

Kata Kunci : nilai tanah, harga tanah, jalan bypass Mataram Gerung

\section{PENDAHULUAN}

Pencapaian kesejahteraan masyarakat Indonesia, salah satunya didukung oleh pertumbuhan ekonomi. Untuk mewujudkan pertumbuhan ekonomi perlu dilakukan pembagunan berkelanjutan. Provinsi Nusa Tenggara Barat (NTB), merupakan bagian dari wilayah Negara Kesatuan Republik Indonesia (NKRI), juga sedang melakukan pembangunan berkelanjutan. Pertumbuhan ekonomi di provinsi ini berasal dari berbagai sektor, antara lain sektor wisata. Sektor wisata di provinsi ini, potensial untuk dikembangkan. Selain karena keindahan alam Provinsi ini, juga karena beberapa acara bertaraf internasional diselenggarakan di provinsi ini, dan juga karena mobilitas masyarakat Provinsi NTB dalam beragam rutinitas kegiatan ekonomi. Mobilitas masyarakat Provinsi NTB tersebut membutuhkan kemudahan dalam mobilisasi dari satu kabupaten ke kabupaten lain baik di Provinsi NTB maupun di luar Provinsi NTB. Dengan adanya pembangunan jalan, diharapkan dapat meningkatkan nilai atau harga tanah disekitar jalan yang dibangun. Sehingga, untuk menunjang pemanfaatan potensi wisata, mendukung terlaksananya beberapa acara bertaraf internasional, dan meningkatkan kemudahan mobilisasi masyarakat maka di Provinsi NTB masih perlu dilakukakan pembangunan sarana transportasi antara lain berupa jalan. 
Sesuai dengan Peraturan Pemerintah Nomor 34 Tahun 2006, Jalan adalah prasarana transportasi darat yang meliputi segala bagian jalan, termasuk bangunan pelengkap dan perlengkapannya yang diperuntukkan bagi lalu lintas, yang berada pada permukaan tanah, di atas permukaan tanah, di bawah permukaan tanah dan/atau air, serta di atas permukaan air, kecuali jalan kereta api, jalan lori, dan jalan kabel. Salah satu sistem jaringan jalan umum adalah jalan bypass. Jalan bypass merupakan jaringan jalan yang tidak ada kewajiban membayar ketika melintasinya. Kabupaten Lombok Barat merupakan salah satu kabupaten di Provinsi NTB. Tahun 2016 di Kabupaten Lombok Barat telah dibangun jalan bypass Gerung-Mataram. Pebangunan jalan bypass ini merupakan bagian pembangunan tahap II jalan bypass Bandara Internasional Lombok (BIL). Pembangunan jalan bypass untuk akses menuju BIL, menyambungkan juga ruas jalan tahap I, yang sudah dapat digunakan. Pembangunan jalan bypass ini dilakukan agar akses menuju bandara dapat dilalui dengan lancar. Jalan bypass ini memiliki panjang delapan kilometer. Jalan bypass terbentang dari Jempong (Kota Mataram) hingga Gerung (Lombok Barat). Selain memudahkan akses bandara, jalan bypass ini juga dapat mengefektifkan perjalanan masyarakat dari Kabupaten Lombok Barat, Kabupaten Lombok Tengah, dan Kabupaten Lombok Timur, menuju ke pusat Kota Mataram. Keberadaan jalan bypass memudahkan aksesibilitas masyarakat terhadap bandara dan daerah lain, yang berdapak juga dalam peningkatan ekspektasi keuntungan terhadap nilai tanah/properti di sekitarnya.

Penelitian ini untuk melihat seberapa besar pengaruh jalan bypass Mataram-Gerung terhadap nilai tanah di Lombok Barat, khususnya meneliti perbedaan nilai tanah dan harga tanah antara kondisi sebelum jalan bypass Mataram-Gerung dibangun dengan kondisi setelah jalan bypass Mataram-Gerung dibangun. Penelitian ini bertujuan menganalisis hubungan sebab akibat antara variabel yang mempengaruhi dengan variabel yang dipengaruhi.

\section{KAJIAN PUSTAKA \\ Perencanaan Kota}

Perencanaan merupakan proses yang berkelanjutan dan menyangkut pengambilan keputusan atau pilihan mengenai tata cara bagaimana memanfaatkan sumber daya yang ada semaksimal mungkin guna mencapai tujuan tertentu di masa yang akan datang (Conyers dan Hill, 1984). Sehingga perencanaan kota dapat diartikan sebagai penyiapan dan antisipasi kondisi kota pada masa depan, dengan titik berat pada aspek spasial dan tata guna lahan, yang dimaksudkan untuk mewujudkan peningkatan kualitas lingkungan kehidupan masyarakat kota dalam mencapai kesejahteraan. Perencanaan kota bisa dipandang sebagai intervensi terhadap perkembangan kota akibat pertumbuhan penduduk dan kegiatan ekonominya. Intervensi yang dapat dilakukan pemerintah meliputi penggunaan lahan, penyediaan layanan umum, dan pembangunan prasarana.

Menurut Todaro (2003), pembangunan ekonomi yang merupakan pemanfaatan hasil dari pembangunan fisik yaitu dengan membangun atau memperbaiki prasarana jalan yang akan menciptakan atau memperbaiki kehidupan masyarakat. Sebagai dampak dari pembangunan jalan, masyarakat dapat menggunakan jalan tersebut untuk berbagai kebutuhan mobilita yang diperlukan seperti mengangkut hasil produksi serta pemasarannya agar menjadi lebih mudah. Jalan dapat dikatakan sebagai urat nadi kelancaran lalu lintas di darat. Lancarnya arus jalan akan sangat menunjang perkembangan sosial dan perekonomian dari suatu daerah. Sehingga pembangunan sarana dan prasarana transportasi jalan akan mempercepat dan mempermudah arus mobilitas barang dan jasa. Peningkatan serta perbaikan infrastruktur pada umumnya akan meningkatkan mobilitas penduduk, menciptakan penurunan ongkos pengiriman barang, sumber daya alam dapat terdistribusikan dengan baik dan meningkatkan kesejahteraan masyarakat serta perbaikan terhadap kualitas dari jasa-jasa angkutan tersebut. 
Konsep mengenai harga, biaya dan nilai dalam ilmu penilaian menurut Standar Penilaian Indonesia (KEPI \& SPI Edisi VII-2018) adalah sebagai berikut:(1). Harga adalah sejumlah uang yang diminta, ditawarkan atau dibayar untuk suatu aset. Karena kemampuan keuangan, motivasi atau kepentingan khusus dari pembeli atau penjual, harga yang dibayarkan mungkin berbeda dengan nilai dari aset tersebut berdasarkan anggapan pihak lain.(2). Biaya adalah sejumlah uang yang diperlukan untuk memperoleh atau menciptakan suatu aset. Ketika aset telah diperoleh atau diciptakan, biaya merupakan suatu fakta. Harga berhubungan dengan biaya, karena harga yang dibayar untuk suatu aset menjadi biaya bagi pembeli.(3). Nilai adalah suatu opini dari manfaat ekonomi atas kepemilikan aset, atau harga yang paling mungkin dibayarkan untuk suatu aset dalam pertukaran, sehingga nilai bukan merupakan fakta. Aset diartikan juga sebagai barang dan jasa.

Jenis nilai dan definisninya dapat dirujuk pada SPI 101 - Nilai Pasar sebagai Dasar Nilai dan SPI 102 - Dasar Nilai selain Nilai Pasar. Karena objek penilaian ini merupakan objek yang dapat diperdagangkan antara pembeli dan penjual tanpa adanya pembatasan atas kegiatannya, maka yang nilai yang digunakan adalah nilai pasar. Merujuk pada SPI 101- Nilai Pasar adalah representasi nilai dalam pertukaran atau sejumlah uang yang dapat diperoleh atau dibayar, atas suatu aset atau liabilitas, jika aset atau liabilitas tersebut ditawarkan untuk dijual di pasar (terbuka) pada tanggal penilaian dan dalam kondisi yang sesuai dengan persyaratan definisi Nilai Pasar.

\section{Teori Pembentuk Nilai Properti}

Faktor-faktor yang dapat membentuk sebuah nilai ada empat unsur (Eldred, 1987:5) yaitu demand, utility, scarcity, dan, transferability. Nilai sebuah properti dapat ditandai dengan adanya keempat unsur tersebut. (1) Demand(Permintaan) akan tanah dan bangunan cenderung akan meningkat akibat adanya pertumbuhan kota atau urbanisasi. Tanah sebagai ruang merupakan tempat bagi masyarakat untuk melakukan aktivitas, sehingga tanah akan selalu dibutuhkan guna memenuhi kebutuhan masyarakat. Padahal jumlah atau luas tanah relatif bersifat tetap atau statis, sehingga untuk memperoleh tanah tersebut masyarakat harus berkompetisi. Kompetisi dalam mendapatkan tanah inilah faktor pemintaan dan penawaran berpengaruh dalam penentuan nilai tanah dan bangunan. Hal tersebut sesuai dengan teori ekonomi yang menyebutkan semakin tinggi permintaan maka akan semakin tinggi harga yang ditawarkan, begitu juga sebaliknya. (2) Utility, merujuk pada kegunaan atau pemanfaatan dari sebuah properti dan sejauh mana property tersebut dapat memenuhi kebutuhan dan keinginan penggunanya. Semakin tinggi pemenuhan manfaat yang dirasakan oleh penggunanya, nilai dari properti tersebut dapat bernilai lebih tinggi. Bisa jadi sebuah property memiliki demand, namun manfaat yang dirasakan oleh penggunanya sedikit, sehingga nilai property tersebut dapat bernilai relatif rendah. (3) Scarcity (kelangkaan tanah) yaitu relativitas tingkat pasokan yang dapat memenuhi kebutuhan pengguna property. Jumlah atau luas tanah yang relatif tetap sementara permintaan tanah yang semakin meningkat membuat tanah menjadi sesuatu yang langka. Kelangkaan tanah ditandai dengan semakin sulitnya mendapatkan tanah untuk memenuhi kebutuhan, khususnya di kota besar yang terus mengalami pertumbuhan penduduk. Konsekuensi dari kelangkaan tanah tersebut sesuai dengan teori ekonomi yaitu semakin besar tingkat kelangkaan maka semakin besar nilai properti. (4) Transferability (dapat dialihkan) mengacu pada proses transfer hak atas properti dari satu pihak ke pihak lainnya. Sebagai sesuatu yang penting bagi manusia, tanah dan/atau bangunan dapat dialihkan oleh pihak yang menguasai tanah dan/atau bangunan kepada pihak lain yang membutuhkannya. Tanah akan menjadi lebih bernilai apabila ia bisa dialihkan kepada pihak lain, karena jika jika tidak tanah hanya akan memiliki arti bagi pemiliknya dan tidak memiliki arti bagi pihak lain.

Ada banyak cara untuk mengalihkan pengusaan tanah dan/atau bangunan, misalnya dengan cara jual-beli, hibah, tukar menukar, dan lain sebagainya. Pengalihan atas properti 
tersebut maka akan diberikan hak yang sesuai, seperti hak milik, hak guna usaha, hak guna bangunan, hak pakai, dan lain-lain. Setiap peralihan hak tersebut sebaiknya dilakukan melalui perbuatan hukum dengan cara membuat bukti peralihan hak yang sah, seperti adanya akta peralihan hak dan pendaftaran hak atas properti tersebut ke instansi yang berwenang.

Terdapat empat faktor yang mempengaruhi nilai tanah dan bangunan (Wolcott, 1987:22-63) antara lain : (a) Faktor ekonomi, dapat ditunjukkan dengan hubungan antara permintaan dan penawaran dengan kemampuan ekonomi dari suatu masyarakat untuk memenuhi keinginan dan kebutuhannya. Variabel permintaan meliputi jumlah tenaga kerja, tingkat pendapatan, tingkat upah dan daya beli, tingkat suku bunga dan biaya transaksi.Variabel penawaran meliputi jumlah tanah yang tersedia, biaya perijinan, pajak dan biaya overhead lainnya; (b) Faktor sosial, ditunjukkan dengan karakteristik penduduk yang meliputi jumlah penduduk, jumlah keluarga, tingkat pendidikan dan karakteristik lainnya. Faktor ini membentuk pola penggunaan tanah pada suatu wilayah; (c) Faktor pemerintah, seperti halnya berkaitan dengan ketentuan perundang-undangan serta kebijakan pemerintah bidang pengembangan dan/atau penggunaan tanah (zoning). Penyediaan fasilitas dan pelayanan oleh pemerintah mempengaruhi pola penggunaan tanah, misalnya fasilitas keamanan, kesehatan, pendidikan, jaringan transportasi, peraturan perpajakan dan lain-lain; dan (d) Faktor fisik, antara lain kondisi lingkungan, tata letak atau lokasi, dan ketersediaan fasilitas sosial.

\section{Uji Beda Independent Sample T-test}

Uji independent sample T-test merupakan uji komparatif atau uji beda untuk mengetahui apakah ada perbedaan rata-rata atau mean yang bermakna antara dua kelompok bebas yang berskala data interval atau rasio.Menurut Ghazali (2012) dalam Magdalena \& Krisanti (2019), Rumus dari uji-t sebagai berikut:

keterangan:

$$
t=\frac{\bar{x}_{2}-\bar{x}_{1}}{\sqrt{\frac{\left(n_{1}-1\right) s_{1}^{2}+\left(n_{2}-1\right) s_{2}^{2}}{n_{1}+n_{2}-2}\left(\frac{1}{n_{1}}+\frac{1}{n_{2}}\right)}}
$$

$\mathrm{t}=$ hasil uji beda independent sample t-test

$\bar{x}_{2}=$ rata-rata sampel kedua

$\bar{x}_{1}=$ rata-rata sampel pertama

$n_{1}=$ jumlah sampel pertama

$n_{2}=$ jumlah sampel kedua

$s_{1}=$ simpangan baku sampel pertama

$s_{2}=$ simpangan baku sampel kedua

\section{METODE}

\section{Rancangan Penelitian}

Dalam penelitian ini, peneliti menggunakan teknik analisis data kuantitatif, yaitu data yang dapat diwujudkan dengan angka yang diperoleh dari lapangan. Dalam penelitian kuantitatif yang dilandasi pada suatu asumsi bahwa suatu gejala itu dapat diklasifikasikan, dan hubungan gejala bersifat kausal (sebab akibat), maka peneliti dapat melakukan penelitian dengan memfokuskan kepada beberapa variabel saja. Pola hubungan antara variabel yang akan diteliti merupakan pola pikir yang menunjukkan hubungan antara variabel yang akan diteliti yang sekaligus mencerminkan jenis dan jumlah rumusan masalah yang perlu dijawab melalui penelitian. Paradigma penelitian ini terdiri atas satu variabel independen dan dependen. Adapun data kuantitatif ini dianalisis oleh penulis dengan menggunakan statistik. Variabel yang mempengaruhi adalah jalan bypass Mataram-Gerung dan variabel yang dipengaruhi adalah nilai tanah;Penelitian ini menggunakan data variabel independen dengan dua kategori yang 
berbeda, yaitu data properti sebelum pembangunan jalan bypass Mataram-Gerung dan data properti setelah pembangunan jalan bypass Mataram-Gerung. Dengan demikian, dilakukan pengujian dengan metode uji beda independent sample t-test untuk dua sampel. Model uji beda ini digunakan untuk menganalisis perbedaan nilai tanah sebelum pembangunan jalan bypass Mataram-Gerung dan nilai tanah setelah pembangunan jalan bypass Mataram-Gerung. Independent sample t-test merupakan salah satu metode pengujian yang digunakan untuk mengkaji keefektifan perlakuan, ditandai adanya perbedaan rata-rata sebelum dan rata-rata sesudah diberikan perlakuan (Widiyanto, 2013).

\section{Populasi dan Sampel (sasaran penelitian)}

Penelitian ini, membutuhkan data tanah sebelum dibangunnya jalan bypass MataramGerung dan data tanah sesudah dibangunnya jalan bypass Mataram-Gerung berdasarkan data transaksi jual beli, dengan rincian sebagai berikut:(a)Tiga puluh data sekunder berupa data transaksi jual beli tanah sebelum dibangunnya jalan bypass Mataram-Gerung dari Badan Pendapatan Daerah Kabupaten Lombok Barat dalam rentang waktu dari tahun 2014 sampai dengan tahun 2015; dan (b) Tiga puluh data sekunder berupa data transaksi jual beli tanah sesudah dibangunnya jalan bypass Mataram-Gerung dari Badan Pendapatan Daerah Kabupaten Lombok Barat dalam rentang waktu dari tahun 2017 sampai dengan tahun 2018.

\section{Teknik Pengumpulan Data dan Pengembangan Instrumen}

Pengumpulan data penelitian dilakukan di sekitar jalan bypass Mataram-Gerung dengan klasifikasi data tercantum pada Tabel 1 Rekapitulasi data sebelum pembangunan jalan bypass Mataram-Gerung dan pada Lampiran Tabel 1 pada Rekapitulasi pengumpulan data setelah pembangunan jalan bypass Mataram-Gerung. Pengolahan data menggunakan software Microsoft Excel untuk pembuatan tabel, analisis, dan pengolahan metode statistik (Uji Beda Independent Sample T-Test);

\section{Teknik Analisis Data}

Pada penelitian ini, secara umum akan dilakukan penilaian dengan pendekatan pasar. Proses penilaian dalam penelitian ini dilakukan untuk mengetahui nilai pasar dari setiap properti, untuk membandingkan perubahan yang terjadi di wilayah sekitar jalan yang menjadi objek penelitian. Nilai pasar dari setiap properti pada penelitian ini diketahui dengan cara melihat harga properti kemudian menentukan berapa penyesuaian (adjustment) yang akan digunakan untuk menentukan nilai properti. Proses penilaian yang dilakukan dalam penelitian ini adalah sebagai berikut:(1) Menggunakan data pasar properti tanah sebelum pembangunan jalan bypass Mataram-Gerung dan sesudah pembangunan pembangunan jalan bypass MataramGerung dalam bentuk transaksi jual beli; (2) melakukan penyesuaian terhadap jenis data atas data properti tanah untuk jenis data penawaran, atau jenis data lainnya;(3)melakukan penyesuaian waktu atas properti pembanding yang diperoleh untuk mendapatkan estimasi nilai pasar Objek Penilaian per Tanggal Penilaian. Tanggal penilaian dalam penelitian ini ditetapkan 1 Januari 2019.(4) melakukan penyesuian (adjustment) terhadap faktor lokasi dan hak-hak yang terkandung dalam properti;(5) teknik penyesuaian yang digunakan dalam penelitian ini adalah teknik penyesuaian persentase (procentage adjustment). Proses penyesuaian dilakukan pada beberapa instrumen sesuai dengan kondisi masing-masing data. Beberapa penyesuaian yang telah dilakukan meliputi penyesuaian jenis transaksi, waktu transaksi, hak atas tanah, dan lokasi. Penyesuaian tersebut bertujuan untuk memperoleh data yang sejenis dan mempunyai nilai wajar. Rekapitulasi data setelah penyesuaian data tercantum pada Lampiran Tabel 2 Rekapitulasi pengolahan data sebelum pembangunan jalan bypass Mataram-Gerung dan Lampiran Tabel 3 Rekapitulasi pengolahan data setelah pembangunan jalan bypass MataramGerung.

Dengan demikian data tersebut dapat diuji dengan menggunakan Uji Beda Independent Sample T-Test. Uji Beda Independent Sample T Test untuk menjawab hipotesa yang dibangun 
bahwa : Ho = Tidak terdapat perbedaan nilai tanah dan harga tanah antara kondisi sebelum jalan bypass Mataram-Gerung dibangun dengan kondisi setelah jalan bypass Mataram-Gerung dibangun. Dan, $\mathrm{Ha}=$ Terdapat perbedaan nilai tanah dan harga tanah antara kondisi sebelum jalan bypass Mataram-Gerung dibangun dengan kondisi setelah jalan bypass Mataram-Gerung dibangun.

\section{HASIL DAN PEMBAHASAN}

Data nilai tanah per $\mathrm{m} 2$ sebelum dan sesudah pembangunan jalan bypass MataramGerung disajikan sebagai berikut: Hasil penelitian digunakan untuk menentukan perbedaan nilai tanah antara kondisi sebelum jalan bypass Mataram-Gerung dibangun dengan setelah jalan bypass Mataram-Gerung dibangun. Berdasarkan Tabel 1 yang merupakan Hasil Pengolahan data Uji Beda Independent Sample T-Test, hasil penelitian sebagai berikut: (1). Rata-rata nilai tanah per $\mathrm{m} 2$ sebelum pembangunan jalan bypass Mataram-Gerung sebesar Rp718.271,67;(2) Rata-rata nilai tanah per $\mathrm{m} 2$ setelah pembangunan jalan bypass Mataram-Gerung sebesar Rp1.227.860,91; (3) Perbedaan nilai tanah per $\mathrm{m} 2$ sebelum pembangunan jalan bypass Mataram-Gerung dan setelah pembangunan jalan bypass Mataram-Gerung sebesar Rp509.589,2; dan $\mathrm{P}(\mathrm{T}<=\mathrm{t})$ one tail atau P-value sebesar 2,169x10-6.

\begin{tabular}{lrr}
\multicolumn{3}{c}{ Tabel 1 Hasil Pengolahan data Uji Beda Independent Sample T-Test } \\
\hline & Variable 1 & \multicolumn{1}{c}{ Variable 2 } \\
\hline Mean & 718271.6744 & 1227860.919 \\
Variance & 48231577369 & $1.91866 \mathrm{E}+11$ \\
Observations & 30 & 30 \\
Pearson Correlatior & 0.07981161 & \\
Hypothesized Mean & 0 & \\
df & 29 & \\
t Stat & -5.887599683 & \\
P(T<=t) one-tail & $1.08453 \mathrm{E}-06$ & \\
t Critical one-tail & 1.699127027 & \\
P(T<=t) two-tail & $2.16906 \mathrm{E}-06$ & \\
t Critical two-tail & 2.045229642 & \\
\hline
\end{tabular}

\section{PENUTUP \\ Simpulan}

Terdapat perbedaan nilai tanah antara kondisi sebelum dibangun jalan bypass MataramGerung dengan setelah dibangun jalan bypass Mataram-Gerung. Dari hasil pengolahan data dengan uji beda independent sample t-test diperoleh perbedaan nilai tanah sebesar Rp509.589,2. Dengan demikian, perbedaan nilai tanah per $\mathrm{m}^{2}$ yang diperoleh dalam penelitian ini sebesar 141,5\%; dan terdapat perbedaan nilai tanah yang signifikan antara kondisi sebelum dibangun bypass Mataram-Gerung dengan setelah dibangunnya bypass Mataram-Gerung. Dari hasi pengolahan data dengan uji beda independent t-test P-value sebesar 2,169x10-6, sehingga p-value lebih kecil dari alpha $(2,169 \times 10-6<0,05)$. Kondisi ini menunjukkan bahwa Ho ditolak dan Ha diterima atau terjadi perbedaan signifikan. Dengan demikian, keberadaan bypass Mataram-Gerung memberikan pengaruh perbedaan nilai tanah per $\mathrm{m}^{2}$ di sekitarnya secara signifikan.

Saran

Karena penelitian ini dibatasai oleh waktu maka hanya dilakukan pada lokasi pembangunan di satu kabupaten, maka penulis sarankan untuk pengembangan penelitian sejenis, sebaiknya dilakukan juga analisa-analisa dampak pembangunan di daerah lain atau 
pendalaman penelitian ke sektor perkembangan transaksi tanah dan atau bangunan setelah adanya suatu pembangunan tertentu di suatu wilayah.

\section{DAFTAR PUSTAKA}

Badan Pusat Statistik. (2021). Diakses 17 Mei, 2021, dari https://ntb.bps.go.id/indicator/3/2/1/ inflasi-gabungan-kota-mataram-dan-kota-bima.html

Badan Pusat Statistik Kabupaten Lombok Barat. (2021). Kabupaten Lombok Barat Dalam Angka 2021. Lombok Barat: Badan Pusat Statistik Kabupaten Lombok Barat.

Magdalena, R., \& Krisanti, M. A. (2019). Analisis Penyebab dan Solusi Rekonsiliasi Finished Goods Menggunakan Hipotesis Statistik dengan Metode Pengujian Independent T-Test di PT.Merck, Tbk . Jurnal TEKNO, Vol.16, No: 1.

Todaro, M.P. (2000). Pembangunan Ekonomi di Dunia Ketiga (H.Munandar, Trans. Edisi Ketujuh ed.). Jakarta: Erlangga

Eldred, G. W. (1987). Real Estate Analysis and Strategy. Amerika: Harper \& Row.

Widiyanto, M. (2013). Statistika Terapan. Jakarta: PT Elex Media Komputindo .

Wolcott, R. C. (1987). The Appraisal of Real Estate American Institute of Real Estate Appraiser. North Michigan, Chicago Illinois. p. 22-63.

Pemerintah Kabupaten Lombok Barat. (2021). Gambaran Umum Kabupaten Lombok Barat. Diakses 13 April 2021 dari https://lombokbaratkab.go.id/sekilas-lobar/gambaranumum/

Republik Indonesia. (2005). Peraturan Pemerintah Republik Indonesia Nomor 15 Tahun 2005 tentang Jalan Tol. Jakarta: Sekretariat Negara

Republik Indonesia. (2006). Peraturan Pemerintah Republik Indonesia Nomor 34 Tahun 2006 tentang jalan. Jakarta . Sekretariat Negara

Direktorat Jenderal Pajak. (2016). Surat Edaran Direktorat Jenderal Pajak Nomor SE/54/PJ/2016 tentang Petunjuk Teknis Penilaian Properti, Penilaian Bisnis, dan Penilaian Aset Tak Berwujud untuk Tujuan Perpajakan. Jakarta: Sekretariat Jenderal Kementerian Keuangan. 